\title{
9
}

\section{(Re)Discovering Organizational Purpose}

\author{
Clara Fontán, Ángel Alloza, and Carlos Rey
}

We find ourselves immersed in a new economic and social cycle which we can name "the economy of intangibles". ${ }^{1}$ This new economy is characterized by a growing share of intangible assets creating business value ${ }^{2}$ and the fact that the perception of success is strongly associated with the recognition expressed by its various stakeholders (i.e. employees, clients, shareholders, suppliers and society in general). As we know, creating value is based on the equilibrium between an organization's capacity to sustain differentiation and the ability to achieve legitimization. ${ }^{3}$ However, traditional analysis of the sources of differentiation and legitimization have changed: while in the past it was about creating new products and services, nowadays companies place value on the ability to manage intangible assets and resources, elements that form a more sustainable source of legitimacy ${ }^{4}$ and are harder to copy. ${ }^{5}$

In this context, purpose emerges as an essential resource that is instrumental in achieving this uncopiable differentiation as well as securing stakeholder trust. ${ }^{6}$ Indeed, recent studies point to the fact that performance of those companies that had a clear sense of purpose improved tenfold between 1996 and 2013 as compared to average performance demonstrated by S\&P 500

C. Fontán $(\bowtie) \cdot$ Á. Alloza

Corporate Excellence-Centre for Reputation Leadership, Madrid, Spain e-mail: clara.fontan@corporateexcellence.org; angel.alloza@corporateexcellence.org

C. Rey

Universitat Internacional de Catalunya,

Barcelona, Spain

e-mail: carlosrey@uic.es 
companies. ${ }^{7}$ Generating an authentic and coherent purpose is fundamental for achieving organizational legitimacy and a good reputation. ${ }^{8}$

Today, citizens demand that organizations create ethical, social, environmental and economic value and thus have a positive impact on the quality and condition of people's lives. Think, for example, in the recent findings that demonstrate "an increase of between $17 \%$ and $33 \%$ of self-determination at work for a corporate objective focused on stakeholders compared to one focused on profits". ${ }^{9}$ However, the gap between expectation and perception is currently very big: only $39 \%$ of citizens believe that organizations work hard to improve people's quality of life and they generally would not mind if $76 \%$ of brands disappeared. ${ }^{10}$ In order to bridge this gap, a deep transformation in corporate leadership, culture and behavior is required. Many are asking CEOs and executives to rethink the role of their companies, their impact and the legacy they will leave for future generations. ${ }^{11}$

As we have seen in previous chapters, purpose is an organization's cornerstone. The role of purpose can be described as follows. Purpose...

- is the key conduit for generating unity throughout an organization;

- fosters leadership development at all levels of the organization;

- acts as a filter for making strategic decisions and establishing the fundamental principles that define the business model;

- provides an overarching framework for organizational agility, stimulating a joint combination of autonomy and alignment that liberates the highest potential in every employee;

- furnishes an organization with the meaning of its activity: the whys and wherefores of its actions, its place in the world and its understanding of its role as a relevant social actor.

In this chapter, we will tackle some fundamental questions for (re)discovering corporate purpose in an approach that integrates the external and internal perspectives of an organization. We will consider purpose as a process that is directed inside-out and is reinforced outside-in, generating connections and identity with different stakeholders. Finally, we will show that corporate purpose can be understood as a co-creation that results from a dynamic dialogue between key stakeholder groups. ${ }^{12}$

Although purpose seems to be a difficult aspect to define, it can always be found. Indeed, "we do not invent a higher purpose; it already exists". ${ }^{13}$ Based on our research and experience, this process has to include at least four undertakings (see Fig. 9.1). 


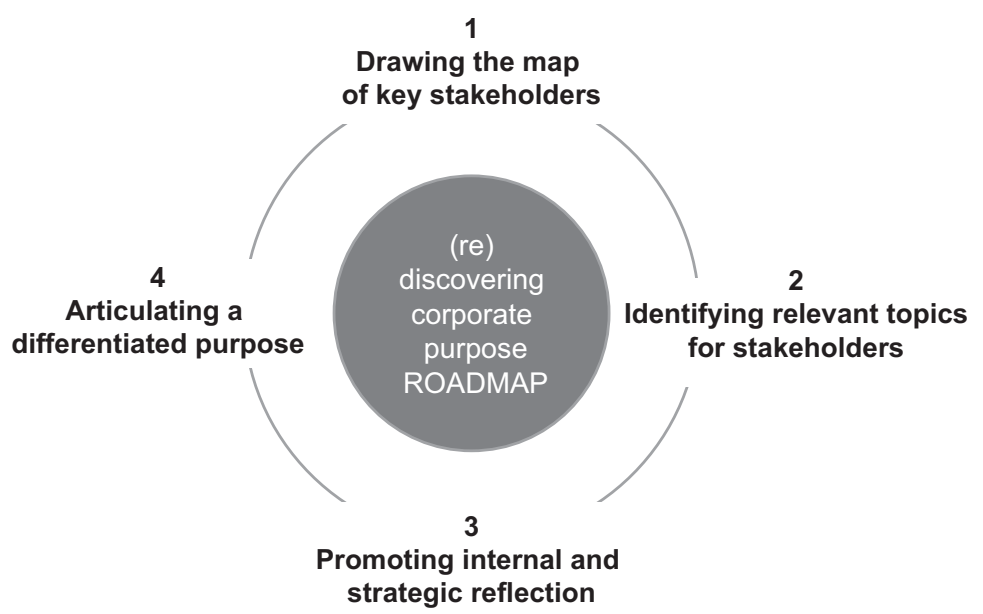

Fig. 9.1 A roadmap for (re)discovering corporate purpose

\section{Drawing the Map of Key Stakeholders}

From an internal perspective, employees have the frontline position to define the corporate purpose. And when setting purpose, companies offer their people an opportunity to participate in a project of superior order and to contribute something worthwhile, ${ }^{14}$ appealing to their fundamental motivations as human beings; to their transcendent motivation. ${ }^{15}$ That is why employees of companies with a strong sense of purpose play such an important role in the process of brand building. They are the first link to an organization's chain of relations. ${ }^{16}$

A good illustration of this is the case of Southwest Airlines. The true key to Southwest's business model and uniqueness resides in the construction of a solid corporate culture around a shared purpose: "connect people to what's important in their lives through friendly, reliable and low-cost air travel". ${ }^{17}$ The company places its own employees at the center of its business model, convinced that their high commitment and satisfaction will translate into good quality service for its customers. As Southwest Airlines' Executive Director and CEO Gary Kelly says, "our people are our single greatest strength and most enduring long-term competitive advantage". Our principles that turn the company's corporate purpose into reality and serve as the basis for its values are a "warrior's spirit", "a servant's heart", and "a fun-living attitude". These three elements host the values that explain the Southwest living way. ${ }^{18}$

When it comes to defining corporate purpose, employees are key, but so are other stakeholders. Under the new logic of purpose, organizational purpose is 
created by cognitive, emotional and active connections to organizational purpose. ${ }^{19}$ By expanding the traditional view of organizational boundaries beyond the traditional legal or competence perspectives, we incorporate a broader view, one based on identity. ${ }^{20}$ In this view, other agents such as clients, shareholders, opinion leaders or experts, top managers or community members can be considered organizational members as much as they identify with the purpose of the organization. ${ }^{21}$ Corporate purpose, rather than being defined for the stakeholders, is defined with them. ${ }^{22}$

Thus, when defining the purpose, companies should reflect upon the key stakeholders that ought to be part of the organization - those agents who are likely to identify with the organizational purpose. Identification and prioritization of these groups is driven by the degree of their potential identification with the organizational purpose and their ability to contribute to its development. An example of this process is found in the corporate purpose definition of BBVA: "Internally, the research exercise sought to identify the culture, values and expectations regarding the company. It explored the vision and values shared by the company's directors and staff at all company levels. Externally, it searched for market trends and stakeholder motivations, as well as direct and indirect competition. In total, BBVA interviewed 100,000 consumers in more than 20 countries. BBVA also undertook 100 focus groups with consumers, shareholders and employees, and 100 in-depth interviews with directors and opinion leaders". ${ }^{23}$ Through this exercise, BBVA placed employees, clients, opinion leaders, shareholders, top management and society as key pieces of the stakeholder's map to define its purpose. But this is not a one-time project. Purpose definition is an ongoing process that evolves over time and is sensitive to internal and external contextual changes. And this is the case for BBVA. ${ }^{24}$ Its identity (future) is stable over time, but the form of its purpose changed from the original form documented in 2003. At that time, BBVA articulated its purpose as "we work to create a better future for people", with the claim "going forward". Today it is defined as: "To bring the age of opportunity to everyone", with the claim "creating opportunities".

\section{Identifying Relevant Topics for Stakeholders}

Nowadays, expectations of an organization's role in society is much higher than in the past: today's citizens support companies for what they represent rather than for the products or services they sell. ${ }^{25}$ They want companies that use their influence to have a positive impact on people's lives and to progress humankind. Creating a meaningful purpose requires not only an understanding of the issues that worry various stakeholders but also, to a certain extent, an 
ability to read trends and understand the logic of society. All in all, it means knowing which big social issues worry one's stakeholders and what the business is expected to do in order to improve this world.

Many companies use Sustainable Development Goals (SDG) as a reference point in the process of identifying their stakeholders' most relevant issues. ${ }^{26}$ This domain incorporates such aspects as hunger, poverty, health, working conditions, consumption, climate and so on. Linking purpose with one of these universal values may be helpful in achieving strong identification with stakeholder groups. ${ }^{27}$ Another referral point is what some call "paying attention to peripheries" 28 by looking at areas where people feel excluded and/or identifying social needs around the organization that have been disregarded or overlooked by society.

In order to identify relevant topics, companies must establish the means of actively listening to the agents that form the organization's stakeholder map. Their perceptions and opinions should be integrated with the analysis of relevant topics. For this, contextual, reputational and social intelligence is needed. ${ }^{29}$ Keeping track of social trends and concerns allows organizations to identify truly relevant topics and narratives. A good example of introducing a system of corporate listening is provided by McDonalds, which used awareness of social concerns to re-focus its brand positioning in the face of a new global challenge, obesity. Another success story is the brand positioning performed by Dove ${ }^{30}$ in the beginning of the 2000s around the concept of "true beauty". Dove decided to redefine its brand position, away from the mere idea of soap, to that which was more in line with the purpose of its corporate brand: create a better future every day. The starting point for positioning the brand around real or natural beauty was determined after studying the conclusions of international research showing that only $2 \%$ of women say that they consider themselves beautiful, and only $12 \%$ are satisfied with their physical appearance. The study also offered more specific data about social pressure reported by women, the result of more recent fashion and beauty trends. All of this gave rise to a campaign entitled: For Real Beauty. The campaign recognized a social concern and took a leading stance on the issue, placing the campaign as a specific narrative, generating socially relevant content aligned with corporate discourse that strengthened the company's stakeholder relations. ${ }^{31}$

\section{Promoting Internal and Strategic Reflection}

The analysis of relevant topics and monitoring of stakeholder opinions and expectations, which includes listening to employees, clients and society, have to be complemented by qualitative meetings among top management. 
Executives must review this information and further engage in the critically important process of defining the organization's distinctive features-its legacy and the future it hopes to build. It does not mean that all companies have to "change the world". Instead, it means being able to commit to a shared belief, which leads a company to make a significant contribution in the areas where it operates.

Drawing on the motivation-knowledge-action dimensions of purpose that we reviewed in the previous chapters, an internal reflection of purpose can be seen as a striking balance between: (1) "want to be" for example, the corporate dream; (2) "have to be" for example, society and stakeholder expectations and (3) "can be" the company's objective capabilities and strengths. The "being" of the organization, found at the intersection of these three circles, is expressed through its purpose (see Fig. 9.2). An example of this relationship is found in Danone, which "wants to be" a company dedicated to health; "has to be" like this because of its consumer expectations, who trust the nutritional value of its products; and "can be" like this through its food production, which is the essence of its business model. The result is the important role that Danone plays in the development and well-being of all citizens in all parts of the world. The intersection of these three dimensions yields its reasons for existence, a purpose of superior order: creating a healthier future.

From a brand perspective, some authors recommend reflecting on purpose by analyzing relevant stakeholder topics in conjunction with the company's history and the impact its products and services might have in tackling such concerns. ${ }^{32}$ In this way, purpose is reinforced by the company's historical legacy, its values and culture and its connection with consumer expectations.

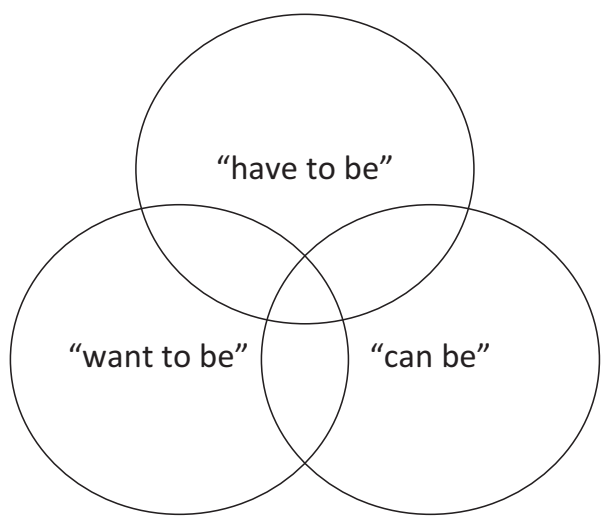

Fig. 9.2 Purpose as the intersection of three dimensions of 'being' 
This turns the purpose on a central axis, sustaining the brand and its chosen direction.

Unilever offers a perfect example of this idea. In the last few years, the company has seen its brands, those that are defined around a purpose, double in economic growth as compared to brands that are not defined by purpose. ${ }^{33}$ Some experts are now claiming this to be the way toward a different model of capitalism, in the long run, a conscious and humanistic capitalism. ${ }^{34}$ In essence, purpose and the values that define it, worked to permeate the organization's leadership style, nudging Unilever to reword and redefine the positioning of all its brands. One of the most relevant projects that they are implementing is the Sustainable Living Plan, which attempts to significantly influence the behavior of employees (more than 170,000), suppliers (about 200,000), clients ( 2 million), partners and even competitors in order to help them choose and maintain a more sustainable way of life. ${ }^{35}$

\section{Articulating a Differentiated Purpose}

There is an irreplaceable imprint that characterizes a great purpose, one which has a positive and beneficial impact in the eyes of the audience. ${ }^{36} \mathrm{~A}$ differentiating purpose must address a critical question: would our stakeholders miss us if we ceased to exist? As some experts suggest, "a great purpose is grounded in something universally true that is authentically delivered by your brand and product" ${ }^{37}$ Think, for example, in the case of Patagonia. The organization was inspired by its founder's values and chose to place a social purpose at the center of its business: "tackle the environmental crisis". By doing this, the company managed to achieve a leading position in the market as a responsible, coherent organization, committed to the environment and generating social value.

Articulating a differentiated purpose is the most creative part of the process, because it implies distilling the corporate purpose to a sentence that can drive the corporate narrative and express the organization's unique contribution to the world. ${ }^{38}$ Corporate branding experts recommend ${ }^{39}$ : (1) be concise by using short phrases, (2) be straightforward by avoiding jargon, (3) seek what is characteristic - "this is us", (4) stay authentic, firmly ingrained in the organization and (5) seek what is timeless, rooted in the past and forward looking to the future. That, for example, is the purpose of Walt Disney, which has been guiding the company for decades: "create happiness by providing the finest in entertainment for people of all ages, everywhere". ${ }^{40}$ Or Nestlés purpose, reflected in three overarching ambitions: Enable healthier and happier 
lives (focusing on nutrition, water and rural development); develop thriving, resilient communities (focusing on sustainability); and steward resources for future generations (with a focus on having zero environmental impact in operations) ${ }^{41}$

Besides, purpose must reach, not only employees, but also the other stakeholders of the company. As some experts suggest, purpose must be "clear enough that the investors, employees, partners, and customers could articulate it". ${ }^{42}$ It can be compared to a song. From the official version, different players can make covers in different styles (pop, rock, heavy, unplugged, symphonic orchestra etc.) but "the key is for everyone to follow the same melody". ${ }^{43}$ Thus, purpose must be expressed in a way that can be used and replicated by different stakeholders without losing its essence. Examples can be seen with Starbucks: "to inspire and nurture the human spirit-one person, one cup and one neighborhood at a time"; or Facebook: "to share and make the world more open and connected".

Finally, purpose must be expressed in a way that favors co-creation with those who are expected to identify with the purpose. Fostering purpose cocreation requires that its articulation invites key stakeholders to become a part of the purpose by participating in the formation of its definition and meaning. Thus, the way purpose is articulated has to impel customers, employees, suppliers and so on, not only to be beneficiaries of the purpose but also cocreators of the same. It has to reflect the aforementioned idea that purpose is not made for the stakeholders but with them. The company's purpose is created by internalization and it is reinforced by identification, which occurs when stakeholders groups identify with it. A good example of this might be the purpose of Nike- "to bring inspiration and innovation to every athlete in the world". In the articulation of its purpose, Nike actively encourages customers (athletes) to inspire each other, offering a narrative — "just do it" - that goes far beyond the products Nike sells. ${ }^{44}$

Once purpose is defined, it has to permeate not only the corporate narrative but also the production of the company's content, brand experience and messaging. However, many organizations fail from this perspective. Indeed, not all companies that have a purpose are recognized by their purpose. Being true to purpose is a necessary condition, but being recognized by purpose requires a joint development of internal and external communications. ${ }^{45}$ Think, for example, in the case of TOMS, whose marketing claim "one for one" promise to deliver a pair of free shoes to a child in need for every sale of their retail product, or Patagonia, whose advertising campaign "Don't buy this jacket" promotes responsible consumption and reinforces the articulation of their purpose; or Zappos, through the values and corporate culture expressed 
in the "delivering happiness" purpose. This approach requires consolidating the corporate brand as the platform for expressing purpose. Thus, the purpose turns into an extremely important tool: the central axis of corporate narrative strategy as well as a platform for relations with stakeholders.

In this chapter, we have discussed how to discover and rediscover a corporate purpose in a way that creates connections between the organization and its stakeholders. We have suggested a roadmap for setting a relevant purpose, aiming to generate an authentic connection with stakeholder groups and mobilize them into supportive behaviors.

\section{Notes}

1. Carreras, E., Alloza, A., \& Carreras, A. (2013). The economy of intangibles and reputation. In Corporate reputation (pp. 19-32). Madrid: LID Editorial Empresarial.

2. Hall, R. (1992). The strategic analysis of intangible resources. Strategic Management Journal, 13(2), 135-144.

3. Suchman, M. (1995). Managing legitimacy: Strategic and institutional approaches. The Academy of Management Review, 20(3), 571-610.

4. Scherer, A. G., Palazzo, G., \& Seidl, D. (2013). Managing legitimacy in complex and heterogeneous environments: Sustainable development in a globalized world. Journal of Management Studies, 50(2), 259-284.

5. Hall, R. (1992). The strategic analysis of intangible resources. Strategic Management Journal, 13(2), 135-144.

6. Sisodia, R. (2016). Four tenets to fix capitalism \& unlock your business's potential. IESE Insight, 31(31).

7. Mackey, J., \& Sisodia, R. (2013). Conscious capitalism. Liberating the heroic spirit of business. Cambridge: Harvard Business Review Press.

8. Carreras, E., Alloza, A., \& Carreras, A. (2013). Corporate reputation. Madrid: LID Editorial Empresarial.

9. Parmar, B. L., Keevil, A., \& Wicks, A. C. (2019). People and profits: The impact of corporate objectives on employees' need satisfaction at work. Journal of Business Ethics, 154(1), 13.

10. Havas Group. (2017). Meaningful brands 2017. Retrieved December 10, 2018, from https://www.meaningful-brands.com/en

11. Canals, J. (2014). Global leadership development, strategic alignment and CEOs commitment. Journal of Management Development, 33(5), 487-502; Raelin, J. (2015). Rethinking leadership. MIT Sloan Management Review, 56(4), 95-96.

12. Hatch, M. J., \& Schultz, M. (2010). Towards a theory of brand co-creation with implications for brand governance. Journal of Brand Management, 17(8), 590-604. 
13. Quinn, R. E., \& Thakor, A. V. (2018, July-August). Creating a purposedriven organization. Harvard Business Review, 78-85.

14. Bailey, C., \& Madden, A. (2016). What makes work meaningful-or meaningless? MIT Sloan Management Review, 57(4).

15. Cardona, P., \& Rey, C. (2008). Management by missions. New York: Palgrave Macmillan.

16. Saleem, F., \& Iglesias, O. (2016). Mapping the domain of the fragmented field of internal branding. Journal of Product \& Brand Management, 25(1), 43-57.

17. Southwest Airlines' purpose. Retrieved December 17, 2018, from https:// www.swabiz.com/html/about-southwest/index.html?int=GNAVABOU TSWA_SBIZ

18. Thomas, M. (2015). Strategic principles at southwest airlines. Strategic Direction, 31(8), 10-12.

19. Rey, C., \& Bastons, M. (2018). Three dimensions of effective mission implementation. Long Range Planning, 51(4), 580-585.

20. Santos, F. M., \& Eisenhardt, K. M. (2005). Organizational boundaries and theories of organization. Organization Science, 16(5), 491-508.

21. Pérez López, J. A. (2014). Foundations of management. Madrid: Rialp.

22. Ind, N., Iglesias, O., \& Schultz, M. (2013). Building brands together: Emergence and outcomes of co-creation. California Management Review, 55(3), 5-26.

23. Alloza, A. (2008). Brand engagement and brand experience at BBVA, the transformation of a 150 years old company. Corporate Reputation Review, 11(4).

24. Ibid.

25. Hollensbe, E., Wookey, C., Hickey, L., George, G., \& Nichols, C. V. (2014). Organizations with purpose. Academy of Management Journal, 57(5), 1227-1234.

26. Mirvis, P., Googins, B., \& Kinnicutt, S. (2010). Vision, mission, values: Guideposts to sustainability. Organizational Dynamics, 39(4), 316-324.

27. Stengel, J. (2012). Grow: How ideals power growth and profit at the world's greatest companies. New York: Crown Business.

28. Almandoz, J., Lee, Y., \& Ribera, A. (2018). Unleashing the power of purpose: 5 steps to transform your business, IESE Insight, 37, Second Quarter, 44-51.

29. Gregory, A., \& Halff, G. (2017). Understanding public relations in the 'sharing economy'. Public Relations Review, 43(1).

30. Jevons, C., Buil, I., Merrilees, B., \& De Chernatony, L. (2013). Introduction: Thought leadership in brand management. Journal of Business Research, 66(1), $1-3$.

31. Bissell, K., \& Rask, A. (2010). Real women on real beauty: Self-discrepancy, internalization of the thin ideal, and perceptions of attractiveness and thin- 
ness in Dove's Campaign for Real Beauty. International Journal of Advertising, 29(4), 643-668.

32. Rodríguez Vilá, O., \& Bharadwaj, S. (2017). Competing on social purpose. Brands that win by tying mission to growth. Harvard Business Review, 94-101.

33. Ind, N., \& Horlings, S. (Eds.) (2016). Brands with a conscience: How to build a successful and responsible brand. London: Kogan Page Publishers.

34. Ibidem.

35. Retrieved December 16, 2018, from https://www.unilever.com/sustainableliving/our-sustainable-living-report-hub/

36. Birkinshaw, J., Foss, N. J., \& Lindenberg, S. (2014). Combining purpose with profits. MIT Sloan Management Review, 55(3), 49.

37. Bonchek, M., \& France, C. (2018). How marketers can connect profit and purpose. Harvard Business Review Digital Articles, 2-5.

38. Flory, M., \& Iglesias, O. (2010). Once upon a time: The role of rhetoric and narratives in management research and practice. Journal of Organizational Change Management, 23(2), 113-119.

39. Greyser, S. A., \& Urde, M. (2019). What does your corporate brand stand for? Harvard Business Review, 97(1), 80-88.

40. Trevor, J., \& Varcoe, B. (2017). How aligned is your organization? Harvard Business Review Digital Articles, 2-6.

41. Chevreux, L., Lopez, J., \& Mesnard, X. (2017). The best companies know how to balance strategy and purpose. Harvard Business Review Digital Articles, $2-5$.

42. Trevor, J., \& Varcoe, B. (2017). How aligned is your organization? Harvard Business Review Digital Articles, 2-6.

43. Greyser, S. A., \& Urde, M. (2019). What does your corporate brand stand for? Harvard Business Review, 97(1), 80-88.

44. Bonchek, M. (2016). How to build a strategic narrative. Harvard Business Review Digital Articles, 2-4.

45. Rodríguez Vilá, O., \& Bharadwaj, S. (2017). Competing on social purpose. Brands that win by tying mission to growth. Harvard Business Review, 94-101. 
Open Access This chapter is licensed under the terms of the Creative Commons Attribution 4.0 International License (http://creativecommons.org/licenses/by/4.0/), which permits use, sharing, adaptation, distribution and reproduction in any medium or format, as long as you give appropriate credit to the original author(s) and the source, provide a link to the Creative Commons licence and indicate if changes were made.

The images or other third party material in this chapter are included in the chapter's Creative Commons licence, unless indicated otherwise in a credit line to the material. If material is not included in the chapter's Creative Commons licence and your intended use is not permitted by statutory regulation or exceeds the permitted use, you will need to obtain permission directly from the copyright holder. 